\title{
Neuroprotective effect of safranal, an active ingredient of Crocus sativus, in a rat model of transient cerebral ischemia
}

\author{
Hamid R. Sadeghnia ${ }^{1,2}$, Hamideh Shaterzadeh ${ }^{2}$, Fatemeh Forouzanfar ${ }^{2}$, Hossein Hosseinzadeh \\ ${ }^{1}$ Pharmacological Research Center of Medicinal Plants, Mashhad University of Medical Sciences, Mashhad, ${ }^{2}$ Division of Neurocognitive \\ Sciences, Psychiatry and Behavioral Sciences Research Center, Mashhad University of Medical Sciences, Mashhad, ${ }^{3}$ Pharmaceutical \\ Research Center, Mashhad University of Medical Sciences, Mashhad, Iran
}

\begin{abstract}
Safranal is a monoterpene aldehyde found in saffron (Crocus sativus L.) petals. It has been previously reported that safranal has a wide range of activities such as antioxidant and anti-inflammatory effects. In this study, we examined the effect of safranal on brain injuries in a transient model of focal cerebral ischemia. Transient focal cerebral ischemia was induced by middle cerebral artery occlusion for $30 \mathrm{~min}$, followed by $24 \mathrm{~h}$ of reperfusion. Safranal in the doses of 72.5 and $145 \mathrm{mg} / \mathrm{kg}$ was administered intraperitoneally at 0,3 , and $6 \mathrm{~h}$ after reperfusion. Neurobehavioral deficit, infarct volume, hippocampal cell loss and markers of oxidative stress including thiobarbituric acid reactive substances (TBARS), total sulfhydryl (SH) content, and antioxidant capacity (using FRAP assay) were also assessed. The focal cerebral ischemia induced a significant increase in the neurological score, infarct volume and neuronal cell loss in the ipsilateral hippocampal CA1 and CA3 subfields $(p<0.001)$ and also oxidative stress markers $(p<0.01)$. Following safranal administration, the total SH content and antioxidant capacity significantly increased, while marked decreases were observed in the neurological score, infarct volume and hippocampal cell loss, as well as TBARS level. This study concluded that safranal had protective effects on ischemic reperfusion injury in the rat model of stroke. Such effects of safranal may have been exerted mainly by suppressing the production of free radicals and increasing antioxidant activity.
\end{abstract}

Key words: safranal, saffron (Crocus sativus L.), middle cerebral artery occlusion (MCAO), cerebral ischemia, oxidative stress.

\section{Introduction}

Despite the ongoing advances in the field of stroke research, consequences of death and disability have remained considerable throughout the world and delivery of successful therapeutics is still a challenge $[23,26]$. Treatment outcomes for ischemic events involve the restoration of blood supply to an ische- mic tissue. However, the reestablishment of oxygen may exacerbate ischemic injury by the generation of inflammatory mediators and toxic levels of oxidative free radicals, terminating in lipid peroxidation, protein synthesis arrest, and finally, cell death $[8,19]$. Currently, in the field of drug discovery for the treatment of cerebral ischemia/reperfusion injury (IRI), 
more and more attention is paid to the neuroprotection of natural compounds from traditional medicinal herbs [32].

Safranal (2,6,6-trimethyl-1,3-cyclohexadiene-1carboxaldehyde, $\mathrm{C}_{10} \mathrm{H}_{14} \mathrm{O}$ ), a monoterpene aldehyde, is the main constituent of saffron (Crocus sativus L.) essential oil [25]. Safranal possesses a wide range of properties such as being anti-oxidant [3,13], anti-inflammatory [9,14], antidiabetic [21,28], antiseizure [11,12,24], anxiolytic [6], anti-hypertensive [16], cytoprotective [4] and anti-carcinogenic [22]. In our previous research, safranal displayed obvious protective effects on brain injury induced by transient global cerebral ischemia in rats [10]. The purpose of this study was to determine whether safranal could ameliorate brain injury after focal middle cerebral artery occlusion (MCAO), which is a model of brain damage that occurs after stroke and is more relevant to clinical situations [2].

\section{Material and methods}

\section{Chemicals}

Safranal (2,3-dihydro-2,2,6-trimethylbenzaldehyde), 2-thiobarbituric acid (TBA), 2,4,6-tris (2-pyridyl)1,3,5-triazine (TPTZ), 5,5'-dithiobis (2-nitrobenzoic acid) (DTNB), and 2,3,5-triphenyltetrazolium chloride (TTC) were purchased from Sigma-Aldrich Company (Saint Louis, MO). Trichloroacetic acid (TCA), sodium acetate, paraformaldehyde, chloral hydrate, glacial acetic acid, hydrochloric acid, ferrous sulfate, tris (hydroxymethyl) aminomethane, and ethylenediaminetetraacetic acid (EDTA) were obtained from Merck Company (Darmstadt, Germany).

\section{Animals and experimental procedure}

Adult male Wistar rats (220-280 g) were obtained from the Animal Center of School of Medicine, Mashhad University of Medical Sciences (MUMS), Mashhad, Iran. The animals were housed under constant temperature $\left(22 \pm 2^{\circ} \mathrm{C}\right)$ and the standard condition of a $12 \mathrm{~h}$ light/dark cycle with free access to food pellets and tap water, ad libitum. All the animals were treated in accordance with the National Institutes of Health Guidance for Care and Use of Laboratory Animals and their use was approved by the Animal Ethics Committee of MUMS. The rats were randomly assigned to five different groups, each with 6-7 rats. Group 1, the sham group, was the only group undergoing surgery without the induction of ischemia, and group 2 was the control group which underwent the MCAO operation and received saline solution intraperitoneally (i.p.). Safranal (72.5, $145 \mathrm{mg} / \mathrm{kg}$, i.p.) was administered to groups 3-4 as the treatment groups, within 0,3 , and $6 \mathrm{~h}$ after MCAO induction.

\section{Focal cerebral ischemia/ reperfusion injury model}

Briefly, the rats were anesthetized with isoflurane $1.5 \%$ and middle cerebral artery occlusion was induced using the filament model, as previously described with some modifications $[18,20]$. A segment of 4-0 nylon monofilament suture with a rounded tip was carefully advanced to the internal carotid artery, approximately $17.5 \mathrm{~mm}$ from the common carotid bifurcation, to occlude the origin of the middle cerebral artery. Thirty minutes after the induction of ischemia, the filament was withdrawn to induce blood reperfusion for $24 \mathrm{~h}$. The body temperature of the rats was maintained at $37 \pm 0.5^{\circ} \mathrm{C}$ through using a heat lamp during the surgery.

\section{Neurological assessment}

The neurological score of each rat was carefully evaluated $24 \mathrm{~h}$ after MCAO induction [30]. For observing the symmetry in the movements of the four limbs, the rats were kept in the air by the tail. The neurological scores were as follows: (3) when all four limbs extend symmetrically, (2) when not all limbs on the left side extended or they extended slowly than those on the right side, (1) when the limbs on the left side had the minimum motion, and (0) when there was no motion of the forelimb on the left side. Neurological examinations were done in 3 to $5 \mathrm{~min}$ utes.

\section{Evaluating cerebral infarct volume}

Using rat brain matrix, six coronal sections (2-mm thickness) between the anterior edge and posterior edge of the brain were collected and incubated with $2 \%$ TTC at $37^{\circ} \mathrm{C}$ for $30 \mathrm{~min}$. The slices were then photographed using a digital camera connected to a computer. Infarct areas were first measured using image analyzer software (Image J, version 1.47). Then, the total infarct volume of each brain was calculated using the following formula [17]:

Corrected infarct volume $=$ (infarct volume - left hemisphere volume) - right hemisphere volume 


\section{Histopathological examinations}

The animals were deeply anaesthetized with chloral hydrate $(400 \mathrm{mg} / \mathrm{kg})$ and transcardially perfused with $100 \mathrm{ml}$ of heparinized phosphate buffered saline (PBS), followed by $100 \mathrm{ml}$ of $4 \%$ paraformaldehyde in phosphate buffer ( $\mathrm{pH}$ 7.4). Brains were carefully removed and postfixed in the same fixative for $24 \mathrm{~h}$, dehydrated, and embedded in paraffin using an automated tissue processor. Coronal brain sections ( $5 \mu \mathrm{m}$, starting at anteroposterior (AP) $-2.6 \mathrm{~mm}$ and ending AP $-5.7 \mathrm{~mm}$ from bregma) were collected. A total of 6 sections per rat were used. Then, the sections were stained with hematoxylin and eosin (H\&E) and examined under a Leica DMRB microscope (Leica, India). Photographs were then taken using a Canon PowerShot S70 digital camera (Canon, Japan) at 200× magnification and cell counts in both the ipsilateral and contralateral sides of the CA1 and CA3 hippocampal areas were scored in a blinded manner [7].

\section{Measuring lipid peroxidation}

The formation of lipid peroxides was measured as malondialdehyde (MDA), which is the end product of lipid peroxidation. In brief, left cerebral portions were homogenized in $0.1 \mathrm{M}$ ice-cold phosphate buffered saline (PBS, $\mathrm{pH} 7.4$ ) and $1 \mathrm{ml}$ of homogenate sample was mixed with $2 \mathrm{ml}$ of TCA-TBA-HCl reagent (15\% TCA, 0.67\% TBA, and $0.25 \mathrm{~N} \mathrm{HCl})$ and heated for $45 \mathrm{~min}$ in a boiling water bath. After centrifuging at $3000 \mathrm{rpm}$ for $10 \mathrm{~min}$, the absorbance of the supernatant was read against the blank at $535 \mathrm{~nm}$. The amount of the produced MDA was calculated using the molar absorption coefficient of $1.56 \times 10^{5} \mathrm{M}^{-1} \mathrm{~cm}^{-1}$ and expressed in $\mathrm{nmol} / \mathrm{g}$ tissue [29].

\section{Assay of ferric reducing/ antioxidant power}

The antioxidant (reducing) power of the brain homogenate samples was measured using the ferric reducing/antioxidant power (FRAP) assay, as previously described [20]. Briefly, $50 \mu \mathrm{l}$ of homogenate was added to $1.5 \mathrm{ml}$ of freshly prepared and prewarmed $\left(37^{\circ} \mathrm{C}\right)$ FRAP reagent $(300 \mathrm{mM}$ acetate buffer, $10 \mathrm{mM}$ TPTZ in $40 \mathrm{mM} \mathrm{HCl}$, and $20 \mathrm{mM} \mathrm{FeCl}_{3}$ in the ratio of $10: 1: 1$ ) in a test tube and incubated at $37^{\circ} \mathrm{C}$ for $10 \mathrm{~min}$. The absorbance of the blue colored complex was read against the reagent blank at $593 \mathrm{~nm}$. The data were expressed as mmol ferric ions reduced to ferrous form per liter (FRAP value) [10].

\section{Assay of total sulfhydryl groups}

All the sulfhydryl (SH) groups were measured using DTNB as the reagent [12]. Briefly, $1 \mathrm{ml}$ of TrisEDTA buffer ( $\mathrm{pH}$ 8.6) was added to $50 \mu$ of homogenate and the sample absorbance was read at $412 \mathrm{~nm}$ against Tris-EDTA buffer alone (A1). Then, $20 \mu \mathrm{l}$ of DTNB reagent $(10 \mathrm{mM}$ in methanol) was added to the mixture and, after $15 \mathrm{~min}$, the sample absorbance was read again (A2). The absorbance of DTNB reagent was also read as a blank (B). Total thiol concentration ( $\mathrm{mM}$ ) was calculated by the following equation:

Total thiol concentration $(m M)=\left(A_{2}-A_{1}-B\right) \times$ $\times 1.07 / 0.05 \times 13.6$

\section{Statistical analysis}

Data were expressed as mean \pm SEM. Multiple comparisons were performed using one-way ANOVA, followed by the Tukey-Kramer post-hoc test. Differences were considered statistically significant at $p<0.05$.

\section{Results}

\section{Effect of safranal on neurological score}

MCAO decreased the neurological score from $3.0 \pm 0.0$ to $0.8 \pm 0.2$, as compared with sham animals ( $p<0.001)$ (Fig. 1). Treatment with safranal at doses of 72.5 or $145 \mathrm{mg} / \mathrm{kg}$ significantly increased the neurological score to $2.5 \pm 0.3(p<0.05)$ and $2.8 \pm 0.2(p<0.001)$, respectively (Fig. 1$)$.

\section{Effect of safranal on infarct size}

Following TTC staining, the living cells were stained deep red, while the infarcted cells remained pale (Fig. 2A). The mean infarct volume in the ischemic group was $155.93 \mathrm{~mm}^{3}$. The extent of the brain infarct size was significantly reduced (by about 6-fold, $p<0.001$ ) after the administration of safranal. As shown in Figure 2B, the mean infarct volumes of 72.5 and $145 \mathrm{mg} / \mathrm{kg}$ safranal groups were $25.48 \mathrm{~mm}^{3}$ and $28.15 \mathrm{~mm}^{3}$, respectively $(p<0.001)$. 


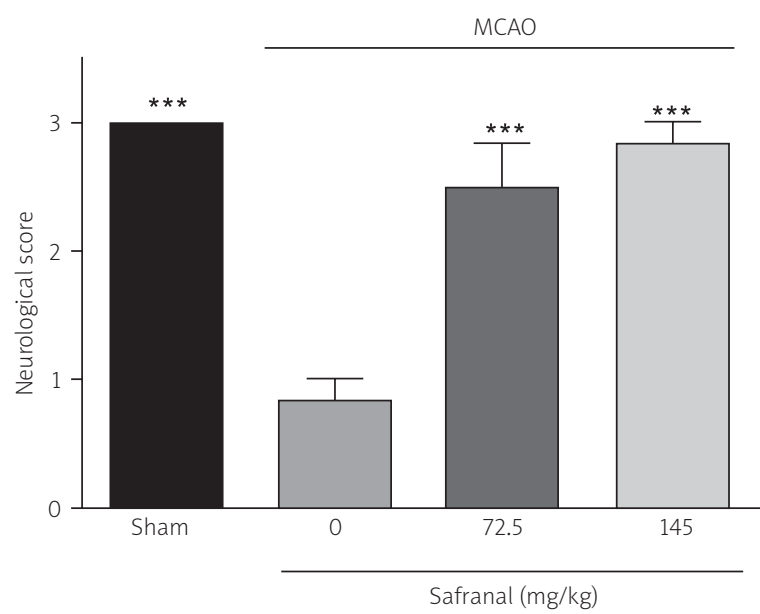

Fig. 1. Effects of safranal on neurological scores in rats subjected to middle cerebral artery occlusion (MCAO) for 30 min and reperfusion for $24 \mathrm{~h}$. Values are expressed as mean $\pm \operatorname{SEM}(n=6-7) .{ }^{* * *} p<0.001$ as compared with the MCAO group.

\section{Effect of safranal on hippocampal cell loss}

Figure $3 \mathrm{~A}$ shows representative photomicrographs of coronal brain sections stained with $H \& E$ from the ipsilateral CA1 area of the hippocampus of sham, MCAO, and safranal-treated stroke rats. Statistical analysis revealed significant neuronal cell loss in the ipsilateral $(p<0.001)$, but not the contralateral, hippocampal CA1 and CA3 subfields of stroke animals compared with the sham group. In addition, there were significant differences in the ipsilateral CA1 and CA3 neuronal cell loss between safranal-treated stroke animals and the MCAO group (Fig. 3B and $3 \mathrm{C}$ ).

\section{Effect of safranal on MDA level}

As illustrated in Figure 4, the level of MDA was $85.87 \pm 9.34 \mathrm{nmol} / \mathrm{g}$ tissue in the sham-operated animals. In contrast, the MDA level markedly increased in the ischemic group $(185.5 \pm 28.4 \mathrm{nmol} / \mathrm{g}$ tissue, $p<0.001)$. Safranal administration at the doses of $72.5 \mathrm{mg} / \mathrm{kg}$ and $145 \mathrm{mg} / \mathrm{kg}$ decreased the MDA levels to $83.2 \pm 9.3(p<0.01)$ and $89.1 \pm 17.0$ $(p<0.05) \mathrm{nmol} / \mathrm{g}$ tissue, respectively (Fig. 4).

\section{Effect of safranal on FRAP value}

Cerebral IRI caused a significant reduction in the FRAP value from $2.58 \pm 0.36$ to $1.26 \pm 0.24 \mu \mathrm{mol} / \mathrm{g}$
A
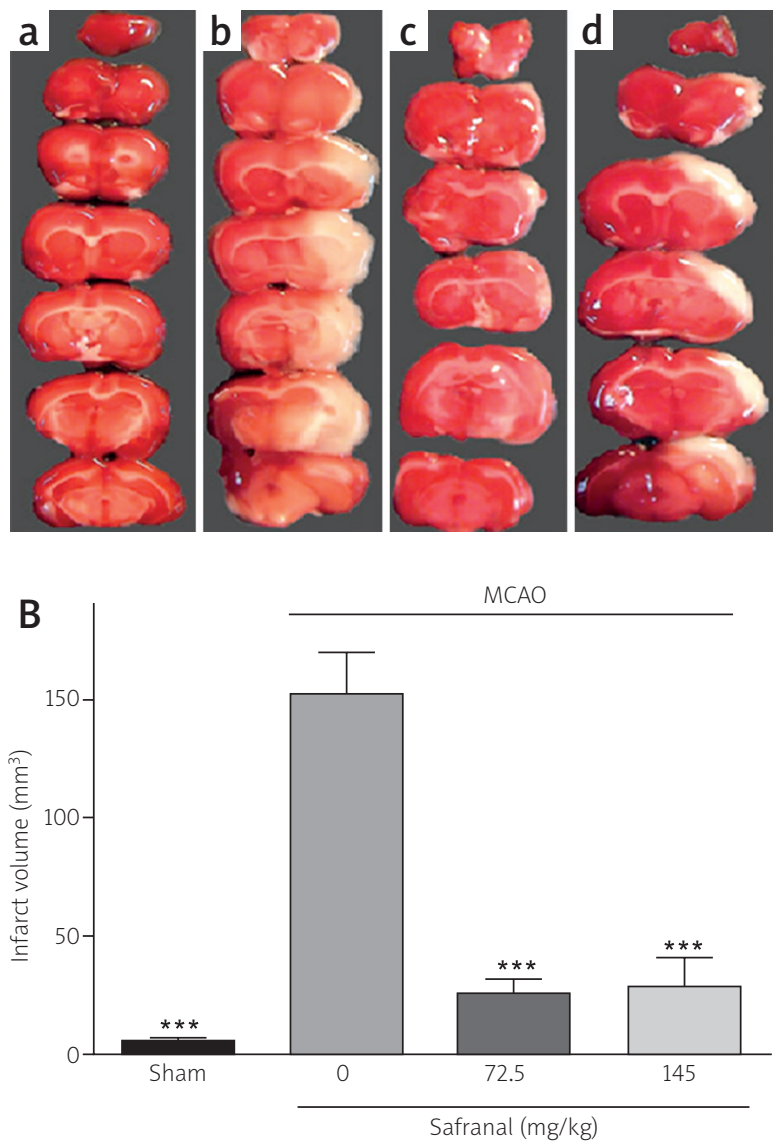

Fig. 2. Effect of safranal on infarct volumes in the rats subjected to middle cerebral artery occlusion (MCAO) for $30 \mathrm{~min}$ and reperfusion for 24 h. A) Representative photographs of 2,3,5-triphenyltetrazolium chloride (TTC) stained coronal brain sections of sham-operated (a), MCAO-operated (b), 72.5 mg/kg safranal-treated (c), and $145 \mathrm{mg} / \mathrm{kg}$ safranal-treated (d) rats. The pale regions indicate the infarcted area and red color stained regions represent normal areas without infarction. B) The bar graph represents volumes of the infarcted area in the rats treated with safranal within 0, 3, and $6 \mathrm{~h}$ after MCAO induction. Values are expressed as mean \pm SEM $(n=6-7) .{ }^{* * *} p<0.001$ as compared with the MCAO group.

tissue, ( $p<0.05$, Fig. 5). As shown in Figure 5, the administration of safranal significantly increased the antioxidant power (FRAP value) of the brain homogenate samples $(3.1 \pm 0.40 \mu \mathrm{mol} / \mathrm{g}$ tissue, $p<0.05 ; 72.5 \mathrm{mg} / \mathrm{kg})$. 
A
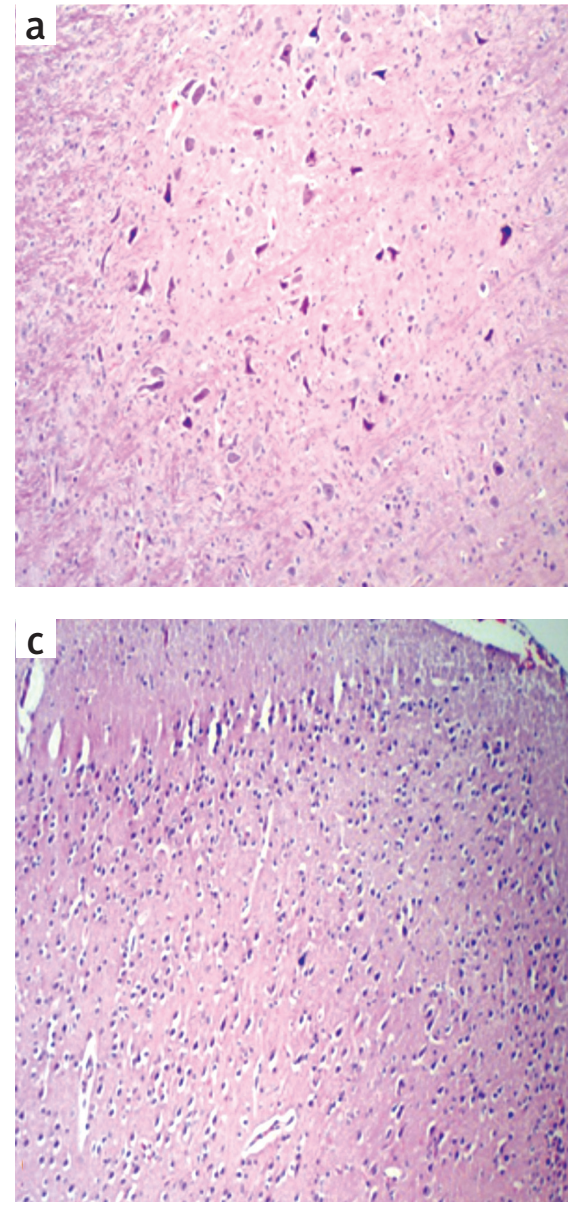

B

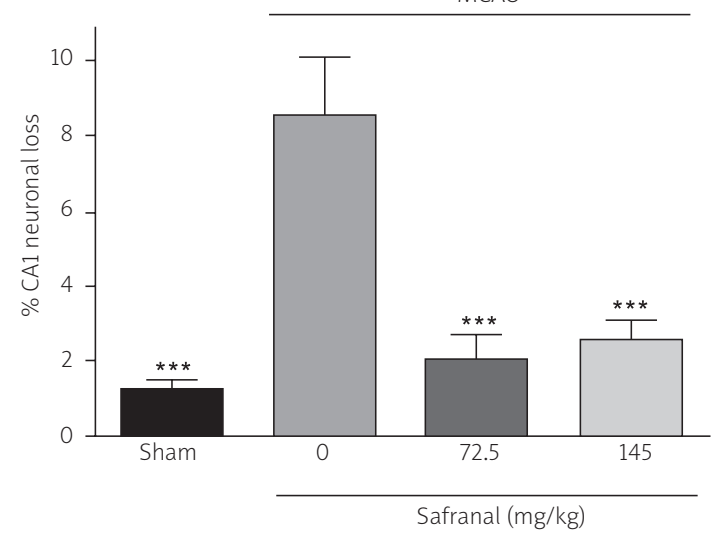

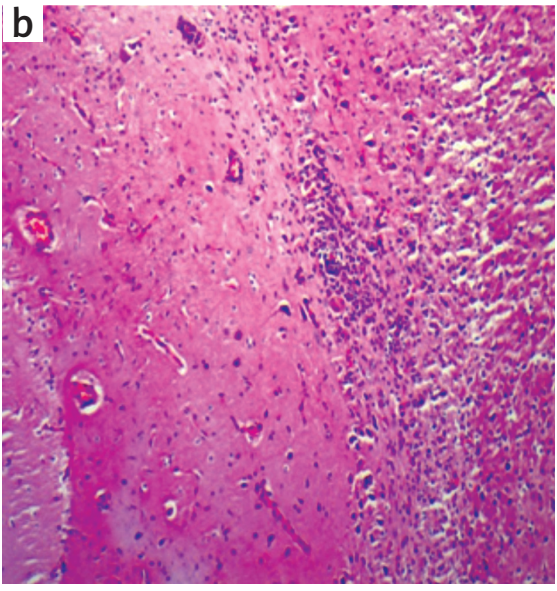

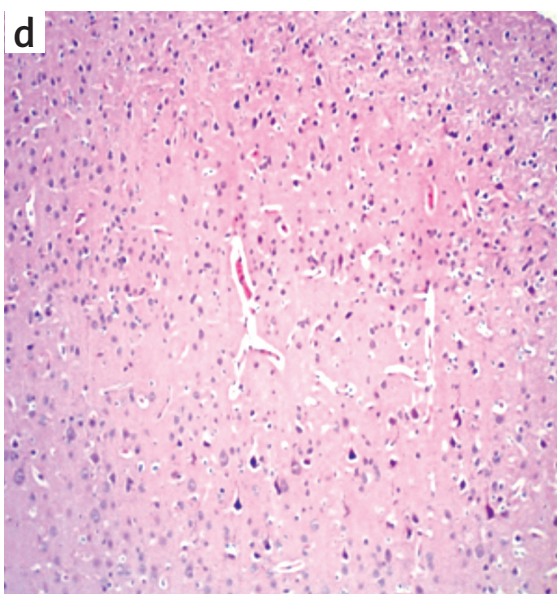

C

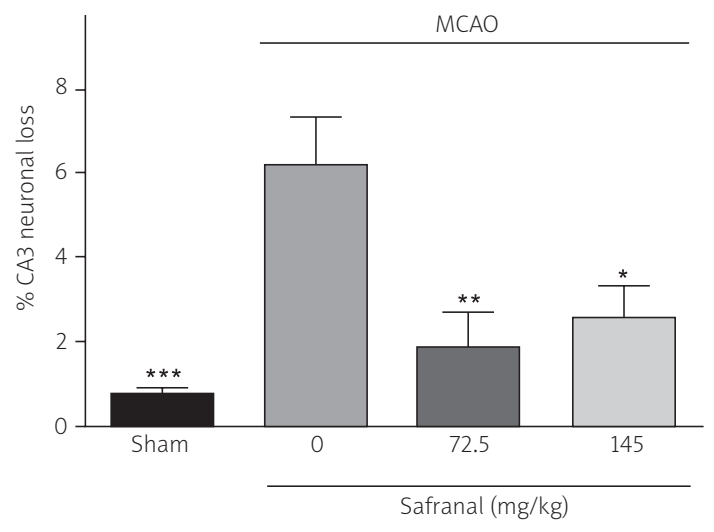

Fig. 3. Effect of safranal on cell density and percentage of degenerated cells in the hippocampal subdivisions of rats subjected to middle cerebral artery occlusion (MCAO) for $30 \mathrm{~min}$ and reperfusion for $24 \mathrm{~h}$. A) Photomicrographs are representative coronal brain sections stained with H\&E from the ipsilateral CA1 area of the hippocampus of sham-operated (a), MCAO-operated (b), $72.5 \mathrm{mg} / \mathrm{kg}$ safranal-treated (c), and $145 \mathrm{mg} / \mathrm{kg}$ safranal-treated (d) rats (200x). B and C) The bar graphs represent percentages of the hippocampal CA1 and CA3 neuronal loss in rats treated with safranal within 0,3 , and $6 \mathrm{~h}$ after MCAO induction. Values are expressed as mean \pm SEM $(n=6-7) .{ }^{*} p<0.05,{ }^{* *} p<0.001$ and ${ }^{* * *} p<0.001$ as compared with the MCAO group. 


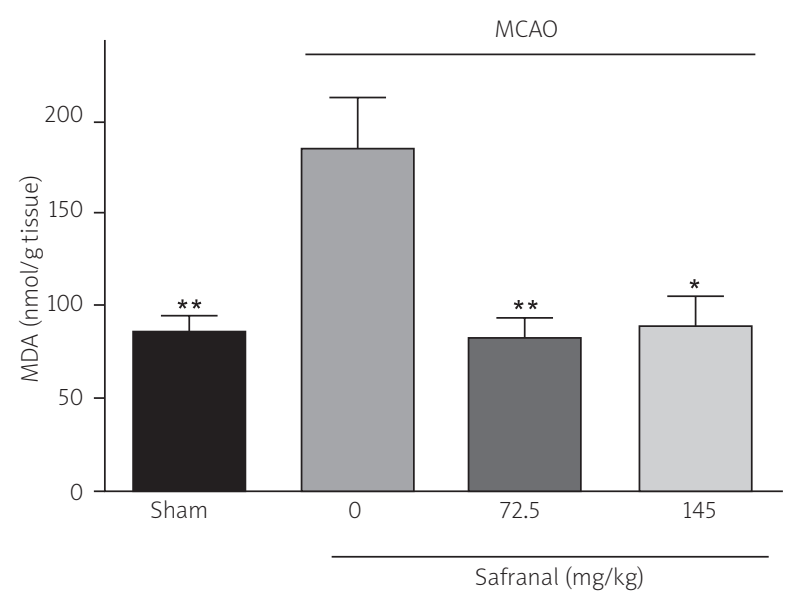

Fig. 4. Effect of safranal on malondialdehyde (MDA) concentration in left cortical regions of rats subjected to middle cerebral artery occlusion (MCAO) for $30 \mathrm{~min}$ and reperfusion for $24 \mathrm{~h}$. The bar graph represents MDA levels in rats treated with safranal within 0,3 , and $6 \mathrm{~h}$ after MCAO induction. Values are expressed as mean $\pm \operatorname{SEM}(n=6-7)$. ${ }^{*} p<0.05$ and ${ }^{* *} p<0.01$ as compared with the MCAO group.

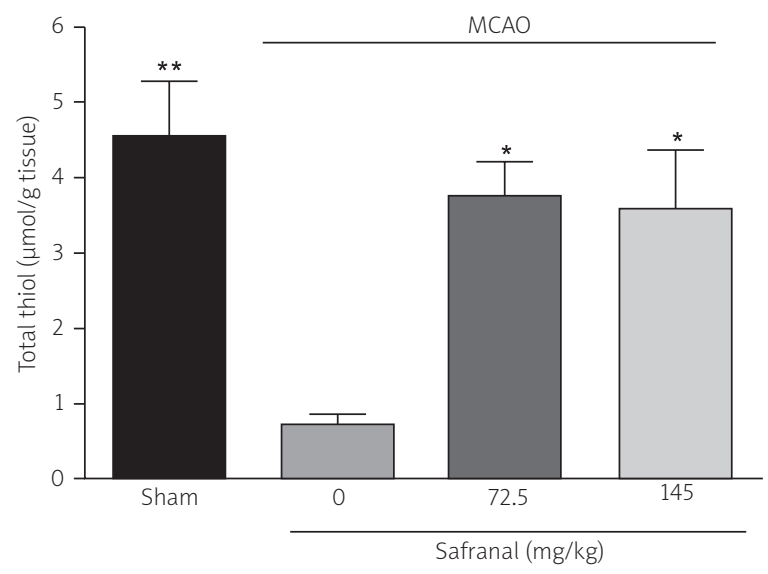

Fig. 6. Effect of safranal on total thiol (SH) content in left cortical regions of rats subjected to the middle cerebral artery occlusion (MCAO) for $30 \mathrm{~min}$ and reperfusion for $24 \mathrm{~h}$. The bar graph represents total thiol levels in rats treated with safranal within 0,3 , and $6 \mathrm{~h}$ after MCAO induction. Values are expressed as mean $\pm \operatorname{SEM}(n=6-7) .{ }^{*} p<0.05$ and ${ }^{* *} p<0.01$ as compared with the MCAO group.

\section{Effect of safranal on total thiol content}

Ischemic insult caused a significant reduction (84.1\%) in the total SH content from $4.5 \pm 0.7$ to

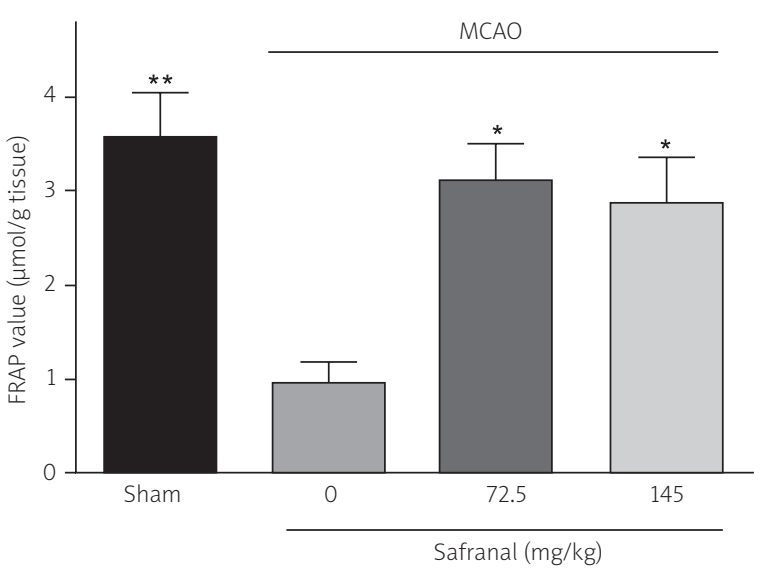

Fig. 5. Effect of safranal on antioxidant status in the left cortical regions of rats subjected to middle cerebral artery occlusion (MCAO) for $30 \mathrm{~min}$ and reperfusion for $24 \mathrm{~h}$. The bar graph represents ferric reducing/antioxidant power (FRAP) values in rats treated with safranal within 0,3 , and $6 \mathrm{~h}$ after MCAO induction. Values are expressed as mean $\pm \operatorname{SEM}(n=6-7)$. ${ }^{*} p<0.05$ and ${ }^{* *} p<0.01$ as compared with the MCAO group.

$0.58 \pm 0.08 \mu \mathrm{mol} / \mathrm{g}$ tissue $(p<0.01$, Fig. 6). Moreover, the administration of safranal at the doses of $72.5 \mathrm{mg} / \mathrm{kg}$ and $145 \mathrm{mg} / \mathrm{kg}$ significantly elevated the total thiol concentration to $3.55 \pm 0.61$ and 3.57 $\pm 0.80 \mu \mathrm{mol} / \mathrm{g}$ tissue, respectively $(p<0.05$, Fig. 6$)$.

\section{Discussion}

In this study, we observed that transient focal ischemia caused significant neurobehavioral deficit, neuronal loss and oxidative stress, indicated by the increase of lipid peroxidation and depletion of total sulfhydryl content and antioxidant power in the brain tissues. The treatment with safranal (72.5 and $145 \mathrm{mg} / \mathrm{kg}$, i.p.) within 0, 3, and $6 \mathrm{~h}$ after MCAO induction significantly decreased the ischemia-mediated neurobehavioral deficit, neuronal cell loss and oxidative damage. The present results also demonstrated that safranal at a low dose (72.5 mg/kg) effectively decreased the ischemiainduced neuronal death and oxidative damage in the brain tissue; however, when administered at a relatively high concentration $(145 \mathrm{mg} / \mathrm{kg})$, the protection against ischemia seemed to be gradually (and not significantly) decreased.

Bharti et al. reported that administration of safranal (0.1-0.5 ml/kg/day corresponding to $87-427 \mathrm{mg} / \mathrm{kg} /$ day, 
i.p.) significantly decreased the infarct size and improved left ventricular functions and myocardium hemodynamic status following myocardial IRI in rats [1]. They also demonstrated that safranal in a dose-dependent manner normalized myocardial antioxidant levels as well as cardiac injury markers (lactate dehydrogenase and creatine kinase $\mathrm{MB}$ ) and diminished the tumor necrosis factor (TNF)- $\alpha$ level, probably due to its fortified antioxidant and anti-apoptotic potential [1]. It was found that safranal $(0.25,0.50$, and $0.75 \mathrm{mg} / \mathrm{kg} / \mathrm{day}$, i.p. for 4 weeks) improved streptozotocin-induced diabetes and its complications by the modulation of oxidative stress markers [28]. Hazman and Ovali also reported that safranal reduced inflammation (TNF- $\alpha$ and IL-1 $\beta$ ) but increased oxidative stress markers due to experimental type 2 diabetes mellitus both in the plasma and pancreas tissue [9]. Maeda et al. found that safranal covalently modified the catalytic cysteinyl thiol of the protein tyrosine phosphatase 1B (PTP1B) in $\mathrm{C}_{2} \mathrm{Cl}_{2}$ myotubes and therefore improved the insulin resistance and glucose tolerance in diabetic $K K-A^{\mathrm{y}}$ mice [21]. It is well documented that inflammatory signaling is involved in all stages of cerebral ischemia [15]. Anti-inflammatory properties have also been reported for safranal [14]. Safranal has shown inhibitory effects on up-regulation of TNF- $\alpha$ and IL-1 $\beta$ in neuropathic rats [33]. Therefore, the inhibition of inflammation may be another reasonable mechanism for alleviating the effects of safranal on ischemic insults. Several phenomena observed during brain ischemia and reperfusion can be attributed to damage to membrane lipids, especially by lipolysis during ischemia and by radical-mediated peroxidation of polyunsaturated fatty acids [31]. Lipid peroxidation is one of the major mechanisms responsible for the cellular damage caused by oxidative stress, and MDA is one of the main end products of lipid peroxidation which is accumulated during ischemia/reperfusion [5]. Hoseinzadeh et al. found that safranal significantly reduced the MDA level in the rat hippocampus [10]. The same authors reported the ability of safranal to reduce the extent of MDA generation in the deoxyribose-induced erythrocyte membrane and liver microsomal non-enzymatic lipid peroxidation [13]. In a recent study, safranal increased the antioxidant defenses by diminishing the lipid peroxidation level and increasing the GSH content of the brain in aged male rats [27]. Safranal also prevented the decrease of hippocampal thiol redox and antioxidant status upon quinolinic acid-induced oxidative damage in the rat hippocampus, suggesting its antioxidant and neuroprotective properties [25].

In conclusion, the present study indicated that safranal had protective effects on ischemic reperfusion injury in the rat model of transient focal cerebral ischemia. According to the results obtained in this study, such protective effects may have been exerted mainly by its antioxidant effects.

\section{Acknowledgments}

The results described in this paper were from a Pharm. D. thesis by Hamideh Shaterzadeh which was supported by the Office of the Vice Chancellor for Research and Technology, Mashhad University of Medical Sciences, under grant number 88402. The authors would like to express their gratitude for this financial support.

\section{Disclosure}

Authors report no conflict of interest.

\section{References}

1. Bharti S, Golechha M, Kumari S, Siddiqui KM, Arya DS. Akt/GSK$3 \beta$ /eNOS phosphorylation arbitrates safranal-induced myocardial protection against ischemia-reperfusion injury in rats. Eur J Nutr 2012; 51: 719-727.

2. Durukan A, Strbian D, Tatlisumak T. Rodent models of ischemic stroke: a useful tool for stroke drug development. Curr Pharm Des 2008; 14: 359-370.

3. Farahmand SK, Samini F, Samini M, Samarghandian S. Safranal ameliorates antioxidant enzymes and suppresses lipid peroxidation and nitric oxide formation in aged male rat liver. Biogerontology 2013; 14: 63-71.

4. Fernandez-Sanchez L, Lax P, Esquiva G, Martin-Nieto J, Pinilla I, Cuenca N. Safranal, a saffron constituent, attenuates retinal degeneration in $\mathrm{P} 23 \mathrm{H}$ rats. PLoS One 2012; 7: e43074.

5. Fu SH, Zhang HF, Yang ZB, Li TB, Liu B, Lou Z, et al. Alda-1 reduces cerebral ischemia/reperfusion injury in rat through clearance of reactive aldehydes. Naunyn Schmiedebergs Arch Pharmacol 2014; 387: 87-94.

6. Fukui H, Toyoshima K, Komaki R. Psychological and neuroendocrinological effects of odor of saffron (Crocus sativus). Phytomedicine 2011; 18: 726-730.

7. Ghorbani A, Mohebbati R, Jafarian AH, Vahedi MM, Hosseini SM, Soukhtanloo M, et al. Toxicity evaluation of hydroalcoholic extract of Ferula gummosa root. Regul Toxicol Pharmacol 2016; 77: 35-41.

8. Ginsberg MD. Current status of neuroprotection for cerebral ischemia synoptic overview. Stroke 2009; 40 (3 Suppl 1): S111-S114.

9. Hazman O, Ovali S. Investigation of the anti-inflammatory effects of safranal on high-fat diet and multiple low-dose strep- 
tozotocin induced type 2 diabetes rat model. Inflammation 2015; 38: 1012-1019.

10. Hosseinzadeh H, Sadeghnia HR. Safranal, a constituent of Crocus sativus (saffron), attenuated cerebral ischemia induced oxidative damage in rat hippocampus. J Pharm Pharm Sci 2005; 8: 394-399.

11. Hosseinzadeh H, Sadeghnia HR. Protective effect of safranal on pentylenetetrazol-induced seizures in the rat: involvement of GABAergic and opioids systems. Phytomedicine 2007; 14: 256-262.

12. Hosseinzadeh H, Sadeghnia HR, Ziaee T, Danaee A. Protective effect of aqueous saffron extract (Crocus sativus L.) and crocin, its active constituent, on renal ischemia-reperfusion-induced oxidative damage in rats. J Pharm Pharm Sci 2005; 8: 387-393.

13. Hosseinzadeh H, Shamsaie F, Mehri S. Antioxidant activity of aqueous and ethanolic extracts of Crocus sativus L. stigma and its bioactive constituents, crocin and safranal. Pharmacog Mag 2009; 5: 419-424.

14. Hosseinzadeh H, Younesi HM. Antinociceptive and anti-inflammatory effects of Crocus sativus L. stigma and petal extracts in mice. BMC Pharmacol 2002; 2: 7-15.

15. Iadecola C, Anrather J. The immunology of stroke: from mechanisms to translation. Nat Med 2011; 17: 796-808.

16. Imenshahidi M, Hosseinzadeh $H$, Javadpour Y. Hypotensive effect of aqueous saffron extract (Crocus sativus L.) and its constituents, safranal and crocin, in normotensive and hypertensive rats. Phytother Res 2010; 24: 990-994.

17. Joshi CN, Jain SK, Murthy PS. An optimized triphenyltetrazolium chloride method for identification of cerebral infarcts. Brain Res Protoc 2004; 13: 11-17.

18. Karabiyikoglu M, Han HS, Yenari MA, Steinberg GK. Attenuation of nitric oxide synthase isoform expression by mild hypothermia after focal cerebral ischemia: variations depending on timing of cooling. J Neurosurg 2003; 98: 1271-1276.

19. Lipton P. Ischemic cell death in brain neurons. Physiol Rev 1999; 79: 1431-1568.

20. Longa EZ, Weinstein PR, Carlson S, Cummins R. Reversible middle cerebral artery occlusion without craniectomy in rats. Stroke 1989; 20: 84-91.

21. Maeda A, Kai K, Ishii M, Ishii T, Akagawa M. Safranal, a nove protein tyrosine phosphatase $1 \mathrm{~B}$ inhibitor, activates insulin signaling in $\mathrm{C} 2 \mathrm{C} 12$ myotubes and improves glucose tolerance in diabetic KK-Ay mice. Mol Nutr Food Res 2014; 58: 1177-1189.

22. Malaekeh-Nikouei B, Mousavi SH, Shahsavand S, Mehri S, Nassirli H, Moallem SA. Assessment of cytotoxic properties of safranal and nanoliposomal safranal in various cancer cell lines. Phytother Res 2013: 1868-1873.

23. Pluta R, Bogucka-Kocka A, Ulamek-Koziol M, Furmaga-Jablonska W, Januszewski S, Brzozowska J, et al. Neurogenesis and neuroprotection in postischemic brain neurodegeneration with Alzheimer phenotype: is there a role for curcumin? Folia Neuropathol 2015; 53: 89-99.

24. Sadeghnia HR, Cortez MA, Liu D, Hosseinzadeh H, Snead OC, 3rd. Antiabsence effects of safranal in acute experimental seizure models: EEG and autoradiography. J Pharm Pharm Sci 2008; 11: $1-14$.
25. Sadeghnia HR, Kamkar M, Assadpour E, Boroushaki MT, Ghorbani A. Protective effect of safranal, a constituent of crocus sativus, on quinolinic acid-induced oxidative damage in rat hippocampus. Iran J Basic Med Sci 2013; 16: 73-82.

26. Saleh MC, Connell BJ, Rajagopal D, Khan BV, Abd-El-Aziz AS, Kucukkaya I, et al. Co-administration of resveratrol and lipoic acid, or their synthetic combination, enhances neuroprotection in a rat model of ischemia/reperfusion. PLoS One 2014; 9: e87865.

27. Samarghandian S, Azimi-Nezhad M, Samini F. Preventive effect of safranal against oxidative damage in aged male rat brain. Experimental Animals 2015; 64: 65-71.

28. Samarghandian S, Borji A, Delkhosh MB, Samini F. Safranal treatment improves hyperglycemia, hyperlipidemia and oxidative stress in streptozotocin-induced diabetic rats. J Pharm Pharm Sci 2013; 16: 352-362.

29. Silva JP, Areias FM, Proença FM, Coutinho OP. Oxidative stress protection by newly synthesized nitrogen compounds with pharmacological potential. Life Sci 2006; 78: 1256-1267.

30. Vafaee F, Zangiabadi N, Pour FM, Dehghanian F, Asadi-Shekaari M, Afshar HK. Neuroprotective effects of the immunomodulatory drug Setarud on cerebral ischemia in male rats. Neural Regen Res 2012; 7: 2085-2091.

31. White BC, Sullivan JM, DeGracia DJ, O'Neil BJ, Neumar RW, Grossman LI, et al. Brain ischemia and reperfusion: molecular mechanisms of neuronal injury. J Neurol Sci 2000; 179: 1-33.

32. Wu PF, Zhang Z, Wang F, Chen JG. Natural compounds from traditional medicinal herbs in the treatment of cerebral ischemia/ reperfusion injury. Acta Pharmacol Sin 2010; 31: 1523-1531.

33. Zhu KJ, Yang JS. Anti-allodynia effect of safranal on neuropathic pain induced by spinal nerve transection in rat. Int J Clin Exp Med 2014; 7: 4990-4996. 